\title{
Investigation on the reaction of iron powder mixture as a portable heat source for thermoelectric power generators
}

\author{
Dale H. Huang • Thanh N. Tran • Bao Yang
}

Received: 1 July 2013/Accepted: 17 December 2013/Published online: 30 January 2014

(C) The Author(s) 2014. This article is published with open access at Springerlink.com

\begin{abstract}
This paper reports our investigation on the thermal behavior and ignition characteristics of iron powder and mixtures of iron with other materials such as activated carbon and sodium chloride in which iron is the main ingredient used as fuel. Thermal analysis techniques such as differential scanning calorimetry (DSC) and thermogravimetric analysis were used to characterize the materials and for further understanding of reaction kinetics of the pyrophoric iron mixtures. The experimental results demonstrated that iron micron particles react exothermically to the oxygen in atmosphere and produced iron oxide with ignition temperature of $427.87^{\circ} \mathrm{C}$ and heat generation of $4,844 \mathrm{~J} \mathrm{~g}^{-1}$. However, in this study, the pyrophoric iron mixture acts as a heat source for the thermoelectric power generators, the final mixture composition is determined to compose of iron powder, activated carbon, and sodium chloride with the mass ratio of approximately 5/1/1. The mixture generated two exothermic peaks DSC curves that showed ignition temperature of 431.53 and $554.85^{\circ} \mathrm{C}$ and with a higher heat generation of $9,366 \mathrm{~J} \mathrm{~g}^{-1}$ at higher temperature. The effects of test pan materials and heating rate on the ignition were also examined by DSC method.
\end{abstract}

D. H. Huang $(\bowtie) \cdot$ B. Yang

Department of Mechanical Engineering, University of Maryland,

College Park, MD, USA

e-mail: dhhuang@umd.edu

B. Yang

e-mail: baoyang@umd.edu

T. N. Tran

Carderock Division, Naval Surface Warfare Center,

West Bethesda, MD, USA
Kinetic data such as the activation energy $\left(E_{\mathrm{a}}\right)$, the entropy of activation $\left(\Delta S^{\#}\right)$, enthalpy of activation $\left(\Delta H^{\#}\right)$, and Gibbs energy of activation $\left(\Delta G^{\#}\right)$ on the ignition processes was also derived from the DSC analysis. From the ignition temperature, heat generation, and kinetics test data, the mass ratio of 5/1/1 proved to generate the most amount of heat with high temperatures for the standalone thermoelectric power generators.

Keywords Ignition - Iron powder - Pyrophoric mixture · Thermal analysis - Thermoelectric

\section{Introduction}

The idea of small size, light mass, robust, scalable, and standalone power generators has always been of great interest in personal and commercial transportation systems. One potential source of portable power is electricity produced from heat sources through the use of thermoelectric materials [1-4]. In general, the heat can come from the combustion of fossil fuels, from sunlight, or as a byproduct of various processes (e.g. combustion, chemical reactions, and nuclear decay). In our study, a pyrophoric iron mixture provides spontaneous heat as soon as it reacts with air. The final mixture of the pyrophoric materials composition was determined to be iron powder, activated carbon, and salt.

Recent research involving heat generation through ignition of powders with different sizes, and in particular, micron-size powders, showed that value of the ignition point and peak temperatures are a strong function of particle size [5]. Thermal analysis study of heterogeneous oxidation of $\mathrm{Fe}$ powder leading to ignition was recently developed and quantified for reaction of iron in environments containing oxygen as the only oxidizer [5]. 
Thermal techniques are powerful methods for the characterization of mixtures of pyrophoric materials. A detailed knowledge of thermal behavior for each component in a mixture or the mixture itself is necessary, not only for safety reasons, but also for predicting the thermal behavior of the new energetic formulations [6]. These are typically based on mixtures of finely divided metal powders with inorganic oxidizing agents [7]. The compositions have a wide range of applications in the production of light, heat, sound, or smoke [7]. A mild heat output is required for compositions that are used as heating pads or hand warmers. However, in this study, the pyrophoric iron powder mixture provides heat, that is then converted to electrical power by the thermoelectric power generator.

Theoretically, due to poor heat transfer in solid state reactions, there is a temperature difference between the center of the solid particles and the surface of the solid particles, in which the temperature was measured [8]. Therefore, one of the key limitations for the study of thermal behavior on multi-component solid state reactions is the inaccuracy of the temperature measurement. One method to increase the accuracy of the temperature measurement is to establish near or perfect homogenous conditions, and this could be achieved by testing very small quantities of the sample using thermal analysis instruments and also performing further analysis on the kinetics of the reactions is recommended [9].

The equipment for thermal analysis have grown rapidly during the past few years. Differential scanning calorimetry (DSC) is used to measure heat flow into or out of a sample as it is exposed to a controlled thermal profile, and gives information about thermal stability, melting, decomposition, etc. [10]. In fact, any release of heat can be detected with this technique [7]. Thermogravimetric analysis (TG) determined the change in mass of the sample when it is exposed to a change in temperature. TG also gives information about thermal stability and decomposition temperatures and it is used as a complementary technique to DSC [10].

At normal temperature, iron is fairly stable in air. In powder form, and especially in the presence of moisture, it oxidizes rapidly. When heated in oxygen, it forms iron oxide, $\mathrm{Fe}_{2} \mathrm{O}_{3}$ [11]. In the past, some researchers have proposed possible use of iron, aluminum, and magnesium, powder as a fuel in pyrophoric systems [12, 13]. For the application of converting heat into electrical power using thermoelectric material made of bismuth telluride, which has the maximum applicable temperature of about $300{ }^{\circ} \mathrm{C}$ on the hot side of the thermoelectric modules. The iron powder is chosen over aluminum or magnesium, because aluminum and magnesium exert a much higher temperature than iron when it reacts with oxygen (see Table 1) and the time duration of maintaining at high temperature regime is
Table 1 Summary of experimental results

\begin{tabular}{|c|c|c|c|c|}
\hline Component & $\begin{array}{l}\text { Composition } \\
\text { mass ratio }\end{array}$ & $\begin{array}{l}\text { Ignition } \\
\text { temp }{ }^{\mathrm{a}} /{ }^{\circ} \mathrm{C}\end{array}$ & & $\begin{array}{l}\Delta H / \\
\mathrm{J} \mathrm{g}^{-1}\end{array}$ \\
\hline $\mathrm{Al}(18 \mu \mathrm{m})[7]$ & $1 / 0 / 0$ & 660 & & \\
\hline $\mathrm{Mg}($ mesh 300) [7] & $1 / 0 / 0$ & 650 & & \\
\hline $\mathrm{Fe}(1-3 \mu \mathrm{m})$ & $1 / 0 / 0$ & 427.87 & & 4,844 \\
\hline $\mathrm{Fe}(4-10 \mu \mathrm{m})$ & $1 / 0 / 0$ & $\begin{array}{l}488.92 \\
\text { Peak } 1\end{array}$ & Peak 2 & 5,435 \\
\hline $\mathrm{Fe}(1-3 \mu \mathrm{m})+\mathrm{C}+\mathrm{NaCl}$ & $21.75 / 1 / 2.25$ & 442.66 & 550.27 & 6,168 \\
\hline $\mathrm{Fe}(1-3 \mu \mathrm{m})+\mathrm{C}+\mathrm{NaCl}$ & $21.75 / 2.25 / 1$ & 442.37 & 561.24 & 8,927 \\
\hline $\mathrm{Fe}(1-3 \mu \mathrm{m})+\mathrm{C}+\mathrm{NaCl}$ & $5 / 1 / 1$ & 431.53 & 554.85 & 9,366 \\
\hline
\end{tabular}

${ }^{a}$ All temperatures shown are at maximum (i.e. peak) heat flux

much shorter than that of iron, thus iron powder is considered to be the ideal candidate for use as the main ingredient of fuel in this system.

Ignition or initiation refers to the point during a chemical reaction at which the rate of heat generation exceeds the required input energy to sustain the reaction, in other words, that is the point at which the reaction becomes selfsustaining [14]. The ignition temperature depends on many variables such as sample mass, test loop configuration, atmosphere conditions, mixture composition, particle shape and size, heating rate, and heat losses.

The objective of this study was also to verify the influences of additional materials such as activated carbon and sodium chloride on thermal decomposition of three pyrophoric material mixtures containing iron powders as fuel. The effect of iron particle size, type of pan materials, heating rate, and kinetic studies were also investigated using DSC method.

\section{Experimental}

\section{Materials}

Two particle sizes of spherical iron powder were purchased from Alfa Aesar. The first powder has the size of 4-10 microns with a purity of $+99.9 \%$ and the second has the size of 1-3 microns with a purity of $+98 \%$. Activated carbon was purchased from Meadwestvaco, and has size ranges in 45-150 microns. Sodium chloride (salt) was used as a catalyst in the reaction.

\section{Instrumentation}

For characterization of the pyrophoric material mixtures, two test set-ups for DSC from thermal analysis (TA) Instruments Co. were used. The first one is using the model DSC 2920 which has a capability of heating up the sample 
to a maximum temperature of $750{ }^{\circ} \mathrm{C}$. The second one is a simultaneous DSC-TG Q Series instrument (SDT Q600) which can perform both DSC and TG at the same time. The SDT measures the heat flow and mass changes associated with phase transitions and reactions in materials over the temperature range of ambient temperature up to $1,500{ }^{\circ} \mathrm{C}$. The information obtained from the test results will be used to differentiate endothermic and exothermic reactions. The endothermic reaction has no associated mass change (e.g., melting and crystallization), while, the exothermic reaction is characterized by the mass changes as the mixture starts to change its properties (e.g., degradation) [9].

\section{Experimental methods}

In our DSC analysis, four samples were prepared and each had an approximate mass of 10.0-18.0 mg. They were placed in different pan materials of aluminum, copper, and ceramic and these were heated at a rate of $10{ }^{\circ} \mathrm{C} \min ^{-1}$ from 20 to $640{ }^{\circ} \mathrm{C}$; the flow rate of oxygen flowing through the DSC standard cell was fixed at $70 \mathrm{cc} \mathrm{min}{ }^{-1}$ at $1 \mathrm{~atm}$. Four samples of the mixture that include iron powder, activated carbon, and sodium chloride with mass ratio of approximately $21.75 / 1$ / $2.25,21.75 / 2.25 / 1,5 / 1 / 1$, and 20/1/1, respectively. Samples that contain pure iron powder with particle size of $1-3$ and 4-10 $\mu \mathrm{m}$ were also prepared for the test.

Three types of pans were also investigated with the DSC testing, and these are aluminum nonhermetic, and hermetic pans, with poked cover hole and open cover and open ceramic pans. TG mass, DSC baseline, and temperature calibrations were performed prior to the experiments to ensure reliability of the test data [14]. The DSC furnace with sample and reference holders was calibrated using a set of certified pure metals.

\section{Results and discussion}

Thermal behavior of the individual components

A single component sample of iron powders (with 1-3 or 4-10 $\mu \mathrm{m}$ particle size) was tested in an oxygen atmosphere to study the oxidation reaction characteristics. The test results are shown in the following Fig. 1. As shown in Fig. 1, the powders exhibited an exothermic reaction peak well below the melting point of iron $\left(1,538{ }^{\circ} \mathrm{C}\right)$. The initial exothermic peaks observed for iron power $1-3 \mu \mathrm{m}$ at $325{ }^{\circ} \mathrm{C}$ and $4-10 \mu \mathrm{m}$ at $200{ }^{\circ} \mathrm{C}$ were due to oxidation of the powder impurities. The reaction peak temperature for 1-3 $\mu \mathrm{m}$ was $427.87^{\circ} \mathrm{C}$, with a total heat generation of $4,844 \mathrm{~J} \mathrm{~g}^{-1}$, and for $4-10 \mu \mathrm{m}$, it was $488.92{ }^{\circ} \mathrm{C}$, with a total heat generation of $5,435 \mathrm{~J} \mathrm{~g}^{-1}$.

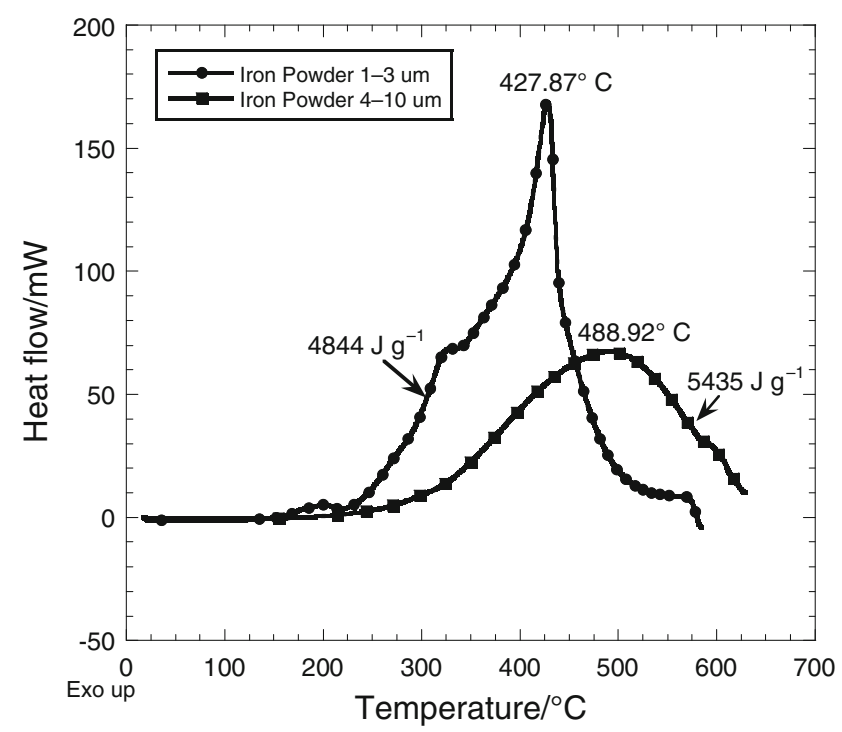

Fig. 1 DSC curves of iron powder with two particle size ranges

Effect of iron particle size

As it has been confirmed by other researchers, the size of reacting particles has a profound effect in energy systems such as propellants and pyrophorics. These reactive systems involve powders, slurries, or dispersions of a solid or liquid in a gas. For solids, whether the particles are spherical or jagged, the particle size is important for performance evaluation [15]. In this study, it is assumed that a particle size refers to the diameter of a hypothetical sphere of the same mass. As shown in Fig. 1, the test results demonstrate that the temperature at which the reaction peaks increases with the particle size. This is presumably caused by having a larger surface area per particle that is readily exposed to the air for a more complete oxidation. Furthermore, a fixed total system volume, containing larger size particles will have a higher void fraction than that of a system with small size particles. Therefore, larger size particles require less initial heat to bring the reacting system up to its activation state, less activation energy, compared to that of the smaller size particles leading to a larger amount of net heat released by the exothermic reaction (larger $\Delta H$ ). In other words, a decrease in particle size requires a higher amount of instantaneous heat flowing into the system to bring it to the activation state, and therefore it has a less net amount of heat released by exothermic reaction (smaller $\Delta H$ ) as shown in Table 1.

Single iron component and iron powder mixture comparison

Mixtures of iron (1-3 $\mu \mathrm{m}$ particle size), activated carbon, and sodium chloride with ratio of $5 / 1 / 1$ by mass were 


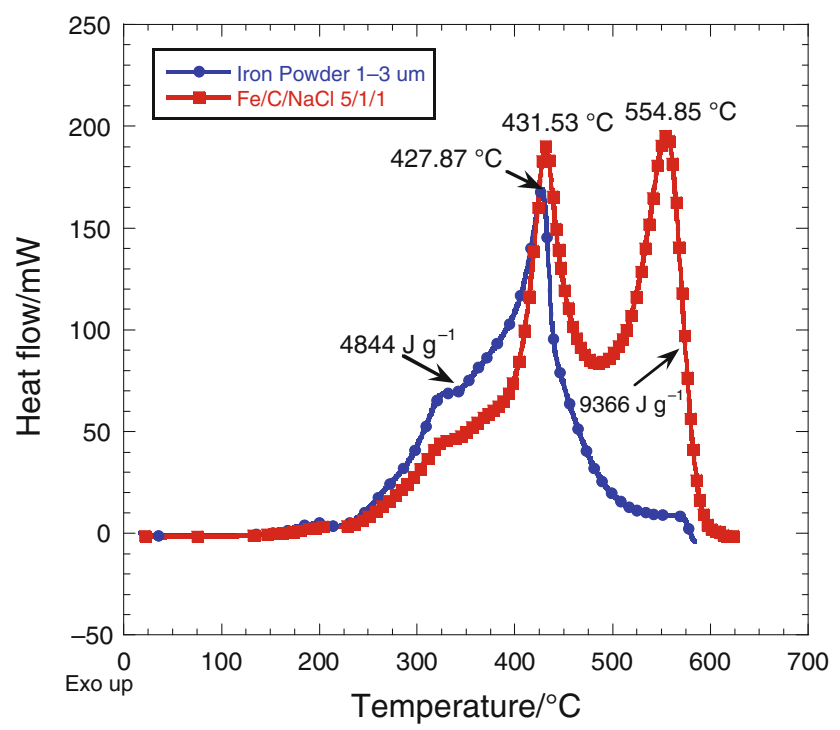

Fig. 2 Comparison of DSC curves of pure iron powder and mixture

prepared and tested with DSC and TG methods. The test results are shown in Fig. 2. In Fig. 2, two exothermic reaction peaks are clearly seen at the temperatures of 431.53 and $554.85^{\circ} \mathrm{C}$; and the total heat generation of $9,366 \mathrm{~J} \mathrm{~g}^{-1}$, which is derived from the area under the curve of these two peaks. Sodium chloride acts as the catalyst that accelerates the exothermic reaction, meanwhile, the activated carbon's role is to store the heat generated by the iron powder. This mixture generates a larger amount of heat compared to that of the single component iron powder sample as shown in Fig. 1. The test results of the pyrophoric iron mixture also show that at $480{ }^{\circ} \mathrm{C}$, which is at the bottom of the first peak, the exothermic reaction provides enough heat to become self-sustaining and therefore, no additional heat is needed to have the reaction continue.

\section{Comparison of DSC and TG analysis}

The oxidation of pyrophoric iron mixtures was also studied by setting up a simultaneous TG-DSC instrument (or SDT Q600), in oxygen atmosphere and the results are shown in Fig. 3. No thermal event was observed prior to $225^{\circ} \mathrm{C}$. However, above this temperature, going into the first step of the oxidation reaction, the iron powder was oxidized to $\mathrm{FeO}$ by oxygen at the peak temperature of $431{ }^{\circ} \mathrm{C}$ as shown by the DSC curve, while the sample mass increased as shown by the TG curve. The oxidation process then continued in the second step of iron oxidation and the product $\mathrm{FeO}$ was oxidized to produce $\mathrm{Fe}_{2} \mathrm{O}_{3}$ at a peak temperature of $554{ }^{\circ} \mathrm{C}$; it was observed that the sample continued to gain mass. This second peak was seen as a shoulder of the first oxidation peak. Thus, the total mass gained for complete oxidation of the iron powder in this test was produced

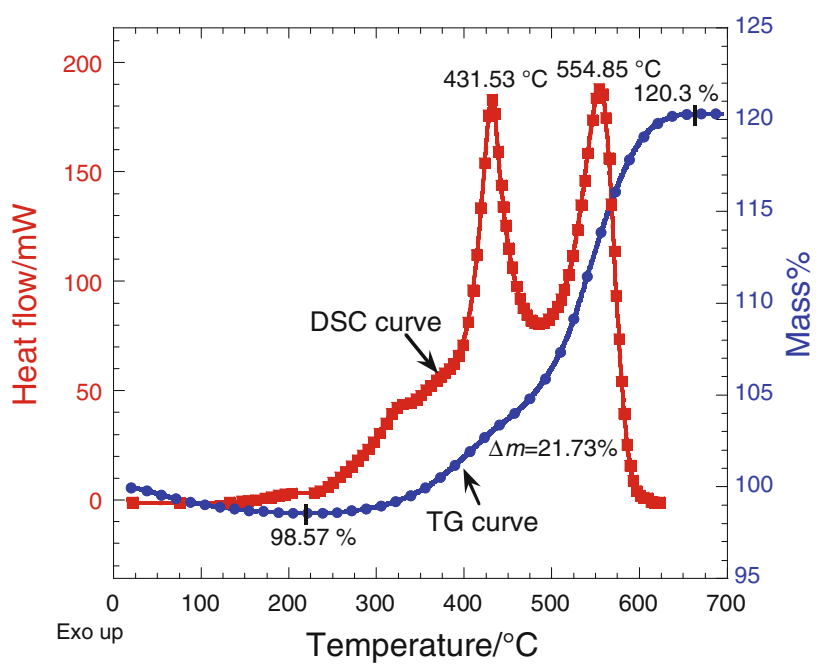

Fig. 3 DSC and TG curves of the pyrophoric iron mixture

by these two reactions and it was about $21.73 \%$. The reaction temperature was in the range of $225-640{ }^{\circ} \mathrm{C}$. A complete exothermic reaction between iron and oxidizer can be expressed as the following

$4 \mathrm{Fe}(\mathrm{s})+3 \mathrm{O}_{2}(\mathrm{~g}) \rightarrow 2 \mathrm{Fe}_{2} \mathrm{O}_{3}(\mathrm{~s})+$ Heat

\section{Comparison of iron powder and mixtures}

A summary of the test results are shown Table 1, where DSC test results of the single component iron powders and the pyrophoric iron mixtures were compared. The mixtures were selected for the following reasons, higher reaction rate and temperature, longer duration of heat sustainability,

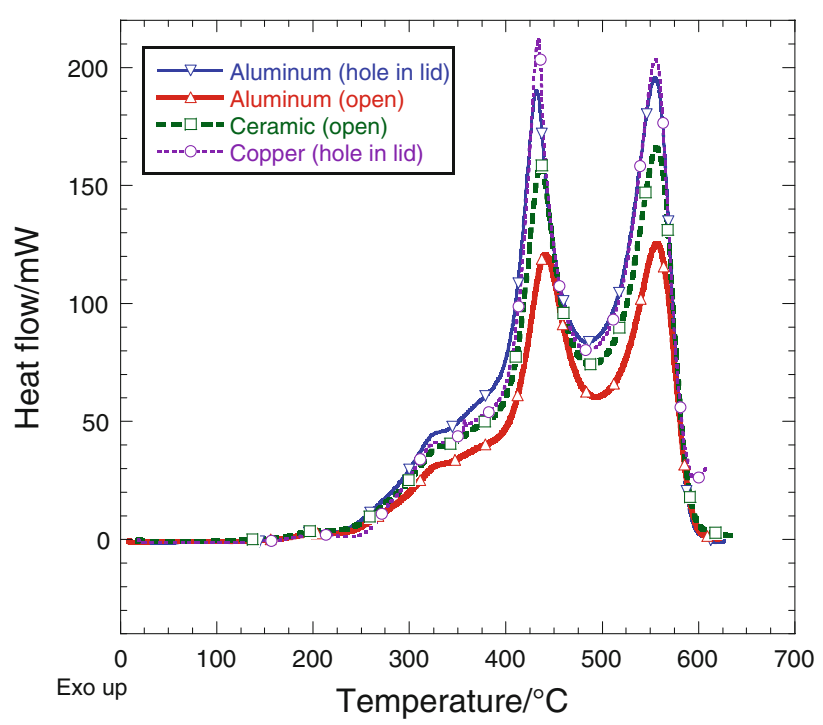

Fig. 4 DSC curves of a mixture tested with multiple pan materials and types 


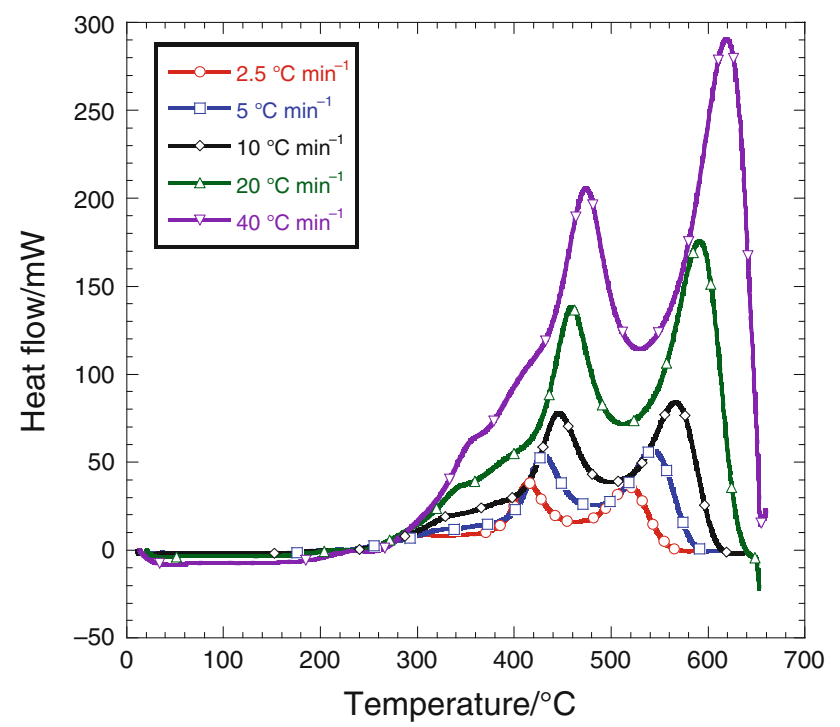

Fig. 5 DSC curves of the mixture under multiple heating rates

and the amount required to bind to the substrate for best heat performance. The results showed that the pyrophoric iron mixtures generated a larger amount of heat $\left(9,366 \mathrm{~J} \mathrm{~g}^{-1}\right)$ than that of the single component iron powder $\left(4,844 \mathrm{~J} \mathrm{~g}^{-1}\right)$. The test results also revealed that a combustion reaction of carbon in the mixture, even at a small mass percent of carbon, does have an effect on the total exothermic reaction of the mixture. Therefore, two temperature peaks in the above Figs. 2 and 3 clearly represent an improvement in thermal behavior of iron and carbon system. The effect of small amount of sodium chloride in the system is negligible at high temperature. This leads to our conclusion that the area under the curve or change in enthalpy of the mixture is should be greater than that of the single component iron powder with $1-3 \mu \mathrm{m}$ particles size.

Table 2 Effect of heating rate on the ignition temperature of the 5/1/ 1 pyrophoric iron powder mixture

\begin{tabular}{lll}
\hline Heating rate $/{ }^{\circ} \mathrm{C} \mathrm{min}^{-1}$ & Peak $1 /{ }^{\circ} \mathrm{C}$ & Peak $2 /{ }^{\circ} \mathrm{C}$ \\
\hline 2.5 & 414.41 & 518.62 \\
5 & 429.32 & 541.65 \\
10 & 444.66 & 565.6 \\
20 & 459.34 & 592.38 \\
40 & 474.30 & 619.21 \\
\hline
\end{tabular}

Why is it so desired to have a higher reaction temperature? The answer is that a higher thermal gradient is needed for the thermoelectric power generator (TPG) application. The thermoelectric power generator (TPG) normally has one hot side and one cold side and the difference between these two sides provides a thermal gradient that acts as a driving force in the conversion of heat to electrical power. TPGs are Carnot heat engines, with electrons performing the work of a working "fluid" [16]. The maximum thermal-to-electric conversion efficiency $\left(\eta_{\max }\right)$ of a TPG is the product of the Carnot efficiency and a materials factor, that depends on the dimensionless thermoelectric figure of merit, $Z T$ (Eq. 1) [16, 17]. For a fixed $Z T$ value, performance of the generator is a function of temperatures. Higher $\Delta T$ between hot and cold sides results in better generator performance. In our study, the pyrophoric iron mixture test results have demonstrated that more amount of powder coated onto the porous silicon carbide substrate, more heat will be provided to the hot side of the thermoelectric modules, which results in a higher thermal gradient, leading to an increase in performance of thermoelectric power generators.

$\eta_{\max }=\frac{T_{\text {hot }}-T_{\text {cold }}}{T_{\text {hot }}} \frac{\sqrt{1+Z T}-1}{\sqrt{1+Z T}+\frac{T_{\text {hot }}}{T_{\text {cold }}}}$.

Effect of pan materials and types

An investigation on the effect of pan materials and types of pans was also carried out for the purpose of distinguishing any effects that could impair the reaction kinetic of iron mixtures. In this study, three types of pan materials were used for DSC analysis of the exothermic reaction of iron mixtures; these materials are aluminum, copper, and ceramic. The test data depict consistent results from different pan materials as shown in Fig. 4; therefore, it is confirmed that the pan materials have no significant effect on the reaction of iron powder mixtures in the temperature range from 25 to $640{ }^{\circ} \mathrm{C}$.

\section{Effect of heating rate}

The oxidation reaction kinetics of iron powder examined by the DSC method was determined by ASTM procedure, which is based on the Ozawa nonisothermal DSC method [18]. Details of the procedure can be found in ASTM Standard E698 for determining the Arrhenius kinetics constants

Table 3 Kinetic parameters for peak 1 and 2 of the 5/1/1 mass ratio iron powder mixture

\begin{tabular}{lllllll}
\hline & $E_{\mathrm{a}} / \mathrm{kJ} \mathrm{mol}^{-1}$ & Frequency factor $\log \mathrm{A} / \mathrm{s}^{-1}$ & $r^{\mathrm{a}}$ & $\Delta G^{\#} / \mathrm{kJ} \mathrm{mol}^{-1}$ & $\Delta H^{\#} / \mathrm{kJ} \mathrm{mol}^{-1}$ & $\Delta S^{\#} / \mathrm{kJ} \mathrm{mol}^{-1}$ \\
\hline Peak 1 & 185.68 & 13.18 & 0.9995 & 186.05 & 179.72 & -8.47 \\
Peak 2 & 147.60 & 8.59 & 0.9999 & 227.55 & 140.61 & -97.43 \\
\hline
\end{tabular}

${ }^{a}$ linear regression coefficient 
of exothermic reactions by DSC [19]. In our study, a pyrophoric iron mixture was prepared with iron powder, activated carbon, and sodium chloride 5/1/1 mass ratio. Five DSC samples from this mixture were tested in aluminum pans from 25 to $640{ }^{\circ} \mathrm{C}$ at the heating rates of $2.5,5.0,10,20$, and $40{ }^{\circ} \mathrm{C} \mathrm{min}{ }^{-1}$. The tests were carried out under an oxygen atmosphere flowing at $70 \mathrm{cc} \mathrm{min}^{-1}$. The pan lid was placed loosely so that oxygen gas could flow through the samples. The heating rates were chosen in such a way that the test data will show two well-defined exothermic peaks within the temperature limit of the instrument. Prior to the test, the DSC cell was calibrated with standard indium metal at the same series of heating rates used in the experiments.

DSC curves from the test results are shown in Fig. 5. The curves show that the temperatures of the peaks are a function of heating rate and they increase with the heating rate. As shown in Table 1, the same trend was also observed for all mixtures. The largest amount of heat obtained from DSC curves was for the 5/1/1 mass ratio mixture at the heating rate of $10{ }^{\circ} \mathrm{C} \mathrm{min}{ }^{-1}$ was $9,366 \mathrm{~J} \mathrm{~g}^{-1}$. The final products from each DSC test had a reddish-black color, which is consistent with the reported color of $\mathrm{Fe}_{2} \mathrm{O}_{3}$.

\section{Kinetics of thermal ignition}

The kinetics of exothermic reactions for these energetic materials are important, since these assessments assure safe testing, handling, storage, and prevention of potential thermal hazards. In this study, the ASTM E698 method was used to determine Arrhenius parameters for the thermally ignited reactions [19]. In order to calculate the pre-exponential factor $(A)$, it is assumed that the reaction is a first-order reaction and this assumption will then be confirmed by the test data. The DSC curves obtained from the test data at various heating rates, for the pyrophoric iron powder mixture with 5/1/1 mass ratio, are shown in Fig. 5. A summary of the test results is shown in Table 2; the maximum peak 1 and peak 2 temperatures $\left(T_{\max }\right)$ and heating rates $(\beta)$ were used in the calculation of reaction kinetics as described in the ASTM E698 method. The plots of the $-\ln \left(\beta / T_{\max }^{2}\right)$ versus $1 / T_{\max }$ for the two peaks are straight lines, which indicates that thermal ignition of these mixtures follows the first-order reaction kinetic law [20]. This finding confirms our earlier assumption on the order of the reaction. The slope of the straight lines was equal to $-E_{\mathrm{a}} / R$, where $E_{\mathrm{a}}$ is the activation energy and $R$ is the gas constant [21]. The log of the pre-exponential factor $(A)$, was calculated from the following $\mathrm{Eq}(2)$ as given in ASTM E698 [19]:

$A=\beta \frac{E_{\mathrm{a}}}{R T_{\max }^{2}} \mathrm{e}^{E_{\mathrm{a}} / R T_{\max }}$

The calculated values of activation energy $\left(E_{\mathrm{a}}\right)$ and preexponential factor $\left(s^{-1}\right)$ for the two peaks of the mixture are summarized in Table 3. The Eyring-Polanyi equation [22, 23], Eq. (3), is used to determine the entropy of activation $\left(\Delta S^{\#}\right)$, enthalpy of activation $\left(\Delta H^{\#}\right)$, and Gibbs energy of activation $\left(\Delta G^{\#}\right)$ corresponding to each peak from the test data. The expression can be shown as the following

$\ln \frac{k}{T_{\max }}=\frac{-\Delta H^{\#}}{R} \frac{1}{T_{\max }}+\ln \frac{k_{B}}{h}+\frac{\Delta S^{\#}}{R}$

where the plots of $\ln \left(k / T_{\max }\right)$ versus $1 / T_{\max }$ form straight lines for peak 1 and 2, and the slopes of these lines equals $-\Delta H^{\#} / R$ and $y$ intercept equal to $\ln \left(k_{B} / h\right)+\Delta S^{\#} / R$, where $k_{B}$ and $h$ are Boltzmann's constant and Planck's constant, respectively, and $T$ is the absolute temperature $(K)[22,23]$. In Table 3, the Gibbs energy of activation equals the enthalpy of activation minus the product of temperature (T) and entropy of activation. In Transition State Theory, the activation enthalpy represents the difference in energy between the ground state of reactants and transition state in a chemical reaction and is similar to the value of activation energy. In general, the reaction will be faster if $E_{\mathrm{a}}$ and $\Delta H^{\#}$ are low and vice versa. All the kinetics results were calculated based on multiple heating rates.

\section{Conclusions}

In this study, the effects of different parameters, such as iron particles size, mixture ingredients, pan materials, heating rate, and reaction kinetics, on the thermal behavior of iron + activated carbon + sodium chloride mixtures were investigated. The results obtained by DSC and TG were used in the data analysis. The results showed that iron powder gains mass in the temperature range between 250 and $580{ }^{\circ} \mathrm{C}$ due to oxidation. Also, it was found that the reactivity of $\mathrm{Fe}$ powder depends on the particle size. The Fe 4-10 micron powders are less reactive in the air and also in the mixture than the Fe 1-3 micron size. Their lower reactivity may be due to having relatively smaller total active surface area of larger iron particles size compared to that of Fe 1-3 micron size particles. On the other hand, the reaction peak width for these mixtures depend on the iron content of the samples and by enhancing the iron content of the mixture, the width of this peak will be increased. The test results indicate that the pyrophoric iron mixtures provide higher heating value than that of a single component iron powder and therefore, it is more suitable for use as a heat source in the portable thermoelectric power generators where higher temperature gradient is desired. Based on the results of this paper, mixtures will continually to be optimized for quicker reaction at high temperature with long periods of time. 
Acknowledgements This research was made possible through the support of the Independent Applied Research program at the Naval Surface Warfare Center, Carderock Division and financially supported by NSF under Grant 1232949 . The authors would like to thank Dr. Steven Dallek of the Spectrum Technology group for his help with the DSC and TG instruments.

Open Access This article is distributed under the terms of the Creative Commons Attribution License which permits any use, distribution, and reproduction in any medium, provided the original author(s) and the source are credited.

\section{References}

1. Lowhorn ND, Wong-Ng W, Lu ZQ, Thomas E, Otani M, Green $\mathrm{M}$, et al. Development of a seebeck coefficient standard reference material. Appl Phys A. 2009;96(2):511-4. doi:10.1007/s00339009-5191-5.

2. Lowhorn ND, Wong-Ng W, Zhang W, Lu ZQ, Otani M, Thomas $\mathrm{E}$, et al. Round-robin measurements of two candidate materials for a seebeck coefficient standard reference material (TM). Appl Phys A. 2009;94(2):231-4. doi:10.1007/s00339-008-4876-5.

3. Lu ZQJ, Lowhorn ND, Wong-Ng W, Zhang W, Thomas EL, Otani M, et al. Statistical analysis of a round-robin measurement survey of two candidate materials for a seebeck coefficient standard reference material. J Res Nat Inst Stand Technol. 2009; 114(1):37-55.

4. Yang B, Liu WL, Liu JL, Wang KL, Chen G. Measurements of anisotropic thermoelectric properties in superlattices. Appl Phys Lett. 2002;81(19):3588-90. doi:10.1063/1.1515876.

5. Zhu XY, Schoenitz M, Dreizin EL. Aluminum powder oxidation in $\mathrm{CO}_{2}$ and mixed $\mathrm{CO}_{2} / \mathrm{O}-2$ environments. J Phys Chem $\mathrm{C}$. 2009;113(16):6768-73. doi:10.1021/jp809816u.

6. Hosseini SG, Eslami A. Investigation on the reaction of powdered tin as a metallic fuel with some pyrotechnic oxidizers. Propellants, Explos, Pyrotech. 2011;36(2):175-81. doi:10.1002/prep. 200900082.

7. Pourmortazavi SM, Hajimirsadeghi SS, Kohsari I, Fathollahi M, Hosseini SG. Thermal decomposition of pyrotechnic mixtures containing either aluminum or magnesium powder as fuel. Fuel. 2008;87(2):244-51. doi:10.1016/j.fuel.2007.04.022.

8. Turcotte R, Fouchard RC, Turcotte AM, Jones DEG. Thermal analysis of black powder. J Therm Anal Calorim. 2003;73(1): 105-18.
9. Vyazovkin S. Thermal analysis. Anal Chem. 2008;80(12): 4301-16. doi:10.1021/ac8005999.

10. Wunderlich B. Thermal analysis. Boston: Academic Press; 1990.

11. Gorrie TM, Kopf PW, Toby S. Kinetics of reaction of some pyrophoric metals with oxygen. J Phys Chem. 1967;71(12): 000-3842.

12. Guidotti RA, Masset P. Thermally activated ("thermal") battery technology-Part I: an overview. J Power Sources. 2006; 161(2):1443-9. doi:10.1016/j.jpowsour.2006.06.013.

13. Guidotti RA, Odinek J, Reinhardt FW. Characterization of $\mathrm{Fe} /$ $\mathrm{KClO}_{4}$ heat powders and pellets. J Energ Mater. 2006;24(4): 271-305. doi:10.1080/07370650600896566.

14. Pourmortazavi SM, Hajimirsadeghi SS, Hosseini SG. Characterization of the aluminum/potassium chlorate mixtures by simultaneous TG-DTA. J Therm Anal Calorim. 2006; 84(3):557-61. doi:10.1007/s10973-005-7008-x.

15. Fathollahi M, Pourmortazavi SM, Hosseini SG. The effect of the particle size of potassium chlorate in pyrotechnic compositions. Combust Flame. 2004;138(3):304-6. doi:10.1016/j.combust flame.2004.06.001.

16. Rowe DM. CRC handbook of thermoelectrics. Boca Raton: CRC Press; 1995.

17. Yang B, Ahuja H, Tran TN. Thermoelectric technology assessment: application to air conditioning and refrigeration. Hvac\&R Res. 2008;14(5):635-53.

18. Ozawa T. Kinetic analysis of derivative curves in thermal analysis. J Therm Anal Calorim. 1970;2(3):301-24. doi:10.1007/ bf01911411.

19. ASTM. Standard E698. Standard Test Method for Arrhenius Kinetic Constants for Thermally Unstable Materials Using Differential Scanning Calorimetry and the Flynn/Wall/Ozawa Method. West Conshohocken, PA: ASTM International.

20. Kissinger HE. Reaction kinetics in differential thermal analysis. Anal Chem. 1957;29(11):1702-6.

21. Eslami A, Hosseini SG, Asadi V. The effect of microencapsulation with nitrocellulose on thermal properties of sodium azide particles. Prog Org Coat. 2009;65(2):269-74.

22. Evans MG, Polanyi M. Some applications of the transition state method to the calculation of reaction velocities, especially in solution. Trans Faraday Soc. 1935;31:875-94.

23. Eyring $H$. The activated complex in chemical reactions. AIP. J Chem Phys. 1935. doi:10.1063/1.1749604. 